\title{
Concepção de suporte organizacional e intenção de rotatividade com base na literatura
}

\author{
Geraldo Eustáquio Moreira \\ Professor Doutor da Universidade de Brasília, Brasília, Brasil. \\ geust@unb.br \\ Míriam Aparecida Mesquita Oliveira \\ Mestranda pela Universidade de Brasília, Brasília, Brasil \\ miriam.oliveira21@gmail.com \\ André Vaz Lopes \\ Mestre Pela Fundação Oswaldo Cruz e Analista administrativo \\ na Agência Nacional de Vigilância Sanitária, Brasília, Brasil \\ andrevazlopes@gmail.com \\ Maria Júlia Pantoja \\ Professora Doutora da Universidade de Brasília, Brasília, Brasil. \\ jpantoja@unb.br
}

Resumo Este trabalho teve como objetivo apresentar uma revisão de literatura acerca da percepção de suporte organizacional e intenção de rotatividade. Para tanto, o foco recaiu em marcos referenciais e artigos da literatura nacional e internacional sobre os referidos temas. Apesar das pesquisas selecionadas não correlacionarem a percepção de suporte organizacional com a intenção de rotatividade dos trabalhadores, elas evidenciaram que a baixa percepção de suporte pode levar a consequências como o absenteísmo e a intenção de rotatividade. Ademais, também demonstraram que a intenção de deixar a organização pode estar relacionada a diversos fatores, entre eles, o baixo nível de percepção de suporte organizacional, a satisfação no trabalho e ao bem-estar do trabalhador.

Palavras-chave: Suporte organizacional, satisfação no trabalho, rotatividade. 


\section{Introdução}

As aceleradas transformações sociais, demográficas, culturais e tecnológicas pelas quais o mundo passa nos últimos anos, faz com que seja necessário que as organizações repensem e reorganizem sua estrutura, processos, organização e condições de trabalho de modo que sejam definidos novos formatos organizacionais.

Para Harman e Horman (1992) a organização, mediante um ambiente de competitividade, precisa atrair e manter os profissionais mais criativos e competentes para garantir sua prosperidade. Isso ocorre devido ao consenso de que os trabalhadores que pertencem à organização possuem poder direto nos resultados de produtividade alcançados pela empresa.

Para que as organizações possam contar com profissionais satisfeitos, motivados e preparados para assumir diferentes tarefas do dia a dia do trabalho, é cada vez mais necessário a preocupação com o bem-estar desses profissionais. Desse modo, identificar e compreender as percepções, os comportamentos e as intenções de comportamentos dos trabalhadores, tem se revelado uma demanda central e de grande relevância e necessidade para a atuação dos gestores.

A literatura revisada neste artigo demonstra que a satisfação ou o elevado nível de percepção de suporte organizacional por parte dos empregados, pode acarretar resultados positivos para a organização, que vão desde a alta produtividade e o alto desempenho até o baixo absenteísmo e a baixa rotatividade.

Este trabalho teve como objetivo geral revisar a literatura acerca dos temas relacionados à percepção de suporte organizacional e intenção de rotatividade. Para tanto, delimitou objetivos específicos tais como: a) analisar as pesquisas realizadas de modo a identificar os fatores que despertam nos trabalhadores a intenção de sair da organização em que trabalham; e b) identificar fatores que influenciam na percepção negativa ou positiva de suporte organizacional.

O presente artigo se divide na revisão da literatura da percepção do suporte organizacional e da intenção de rotatividade, sendo que ao final apresentam-se as considerações a partir da revisão realizada.

\section{Concepção de suporte organizacional}

As crenças e as expectativas dos indivíduos sobre o reconhecimento oferecido pela organização como forma de retribuição pelo trabalho realizado são fatores ligados diretamente à percepção do suporte organizacional. Para Siqueira e Gomide (2004), qualquer indivíduo é capaz de desenvolver percepções muito particulares acerca do trabalho que desenvolve, seja como um todo ou sobre algum aspecto específico.

A percepção do suporte organizacional, conforme Eisenberger et al. (1986, p. 501), pode ser definida como um conjunto de "crenças globais desenvolvidas pelo empregado 
sobre a extensão em que a organização valoriza suas contribuições e cuida de seu bemestar”. É a percepção dos empregados acerca da qualidade do tratamento recebido, ou seja, o quanto a organização cuida de seu bem-estar e como seus esforços são valorizados e retribuídos.

Para Oliveira-Castro, Pilati e Borges-Andrade (1999), a organização tem obrigações legais, morais e financeiras com seus trabalhadores e, como consequência, o trabalhador tem o dever de apresentar bom desempenho e comprometimento com a instituição. Para esses autores, as percepções desenvolvidas pelo indivíduo são baseadas na frequência, intensidade e sinceridade das manifestações organizacionais dispensadas em retribuição ao esforço de seus funcionários. Uma percepção favorável do suporte organizacional permite fortalecer o esforço do empregado com a organização. Nesse caso, o trabalhador somente desenvolve percepções favoráveis do suporte organizacional quando entende que as retribuições organizacionais são sinceras, bem intencionadas e não manipuláveis (Oliveira-Castro; Pilati; Borges-Andrade, 1999).

Eisenberger et al. (1986) consideram que as interações dos trabalhadores com a organização são caracterizadas por meio das trocas relacionadas pelas expectativas de reciprocidade. Nesse caso, a reciprocidade explica o relacionamento entre o trabalhador e a organização, uma vez que os empregados formam percepções genéricas acerca das intenções e dos atos a eles direcionados. Isso ocorre, a partir do entendimento de como seus dirigentes praticam as políticas e procedimentos relacionados à gestão de pessoas, atribuindo características humanas com a organização e acreditando manter relações sociais com ela (Siqueira, 2005).

Siqueira (2005) sugere que para que a reciprocidade seja corretamente utilizada como base na compreensão da percepção do suporte organizacional, o trabalhador deve ser posicionado como receptor e a organização como doadora. A relação de troca entre doador e receptor passaria a ser utilizada na organização a partir de um esquema mental, conforme representado na Figura 1.

Figura 1 - Percepção de suporte organizacional como crenças do empregado receptor

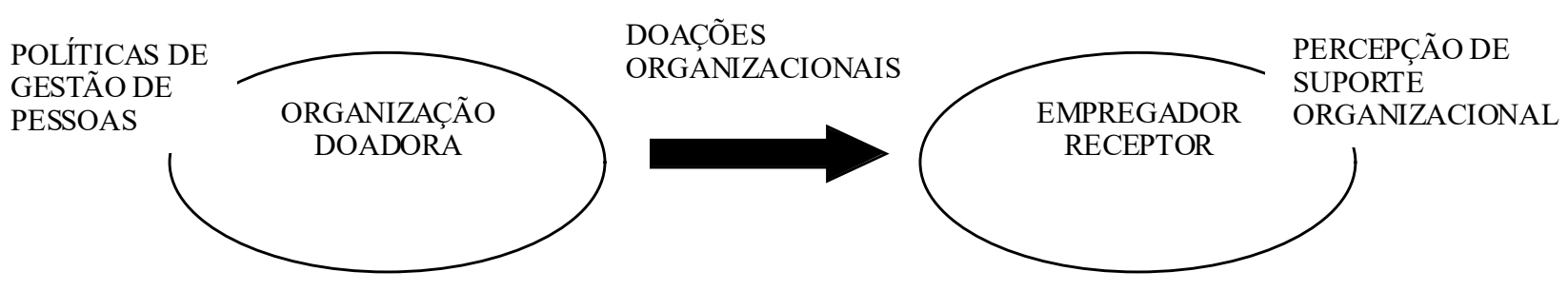

Fonte: Siqueira e Gomide (2004).

A partir da percepção deste suporte, o empregado passa a possuir o sentimento de devedor, passando a ver a organização como credora e merecedora de esforços, além do contrato formal (Silva; Cappellozza; Costa, 2014). Da mesma forma, o empregado também enxerga a organização como devedora quando oferece a ela, favores voluntários. 
O sentimento de que a organização oferece cuidados, reconhecimento e respeito para com seus funcionários pode fazê-los satisfazer necessidades socioemocionais, uma vez que passam a sentirem-se membros da organização (Siqueira; Padovam, 2008).

Siqueira e Gomide (2004) classificam os antecedentes de percepção de suporte organizacional em três fatores: justiça na distribuição de recursos; suporte oferecido pelas chefias; e retornos organizacionais.

O desenvolvimento da percepção do suporte organizacionalé motivado pela tendência dos trabalhadores em atribuir à organização características humanas (Einsenberg et al., 1986). Para Tamayo e Tróccoli (2002), a organização atua por meio do comportamento individual de seus membros-chave, ocupantes de posições de gerência ou de liderança e não de maneira abstrata. Sendo assim, para Levinson (1965), a personificação da organização pode acontecer devido a diversos fatores. Primeiro, porque a organização possui responsabilidades legais, morais e financeiras pelas ações de seus agentes; segundo, pois a permanência ou a extinção de determinados papéis comportamentais devem-se aos precedentes, tradições, políticas e normas organizacionais; e, por último, porque a organização por meio de seus agentes exerce poder sobre seus colaboradores.

A influência da percepção do suporte organizacional em alto nível pode trazer diversos benefícios para a organização, desde a redução do absenteísmo até a intenção de sair da empresa, além disso, traz aumento do desempenho, maior comprometimento e satisfação com o trabalho, conforme demonstrado na Figura 2.

Figura 2 - Antecedentes e consequências de percepção de suporte organizacional

\begin{tabular}{|c|c|c|}
\hline \multirow{5}{*}{$\begin{array}{l}\text { Antece dentes } \\
\text { Justiça de } \\
\text { procedimentos } \\
\text { Suporte de chefias } \\
\text { Retribuições } \\
\text { organizacionais }\end{array}$} & \multirow{4}{*}{$\begin{array}{l}\text { Percepção de } \\
\text { suporte } \\
\text { organizacional }\end{array}$} & \multirow{6}{*}{$\begin{array}{l}\text { Consequências para } \\
\text { Organizações } \\
\text { Menos faltas no trabalho } \\
\text { Menor intenção de sair da } \\
\text { empresa } \\
\text { Maior desempenho } \\
\text { Maior satisfação no } \\
\text { trabalho } \\
\text { Maior comprometimento } \\
\text { organizacional, afetivo, } \\
\text { calculativo e normativo } \\
\text { Maior comprometimento } \\
\text { afetivo com a equipe } \\
\text { Mais cidadania } \\
\text { organizacional }\end{array}$} \\
\hline & & \\
\hline & & \\
\hline & & \\
\hline & & \\
\hline & & \\
\hline & & \\
\hline
\end{tabular}

Fonte: Siqueira e Gomide (2004).

Com base nos estudos de suporte organizacional, Eisenberger et al. (1986) com o objetivo de medir as variáveis que afetam diretamente o desempenho e o comprometimento dos trabalhadores com a organização e com base na abordagem teórica que traz conceitos como reciprocidade, ideologia da troca e modelo motivacional de esforço-resultado, desenvolveram o instrumento Survey of perceived organizational support - SPOS (Oliveira- 
Castro; Pilati; Borges-Andrade, 1999). Para Eisenberg et al. (1986), tal instrumento tem como finalidade medir a avaliação realizada pelos trabalhadores a respeito das retribuições e dos benefícios oferecidos pela organização em troca do seu esforço no trabalho.

O instrumento desenvolvido por Einseberg et al. (1986), possui duas formas, uma completa (composta por 36 itens) e outra reduzida (com 17 itens), nas quais os empregados assinalam em escala positiva ou negativa sua visão sobre as contribuições e o bem-estar organizacional. Os itens são classificados em uma escala tipo Likert, em que 1 significa "Discordo Totalmente" e 7, "Concordo Totalmente".

$\mathrm{Na}$ tentativa de analisar e sistematizar os estudos realizados nessa temática, Eisenberger et al. (2002), realizaram uma metanálise com mais de 70 pesquisas estabelecendo como critério de seleção aquelas que foram realizadas com o instrumento SPSS. Foram levantadas as variáveis já estudadas e as principais hipóteses, antecedentes, consequentes, bem como a correlação entre elas. O resultado dessa análise mostrou que, basicamente, a área apresenta três importantes antecedentes da percepção do suporte organizacional, incluindo procedimentos justos da organização, suporte e recompensas do gerente e condições de trabalho.

Para Oliveira-Castro, Pilati e Borges-Andrade (1999), apesar da importância de estudos relacionados a essa temática, escalas de suporte organizacional ainda são pouco difundidas no Brasil. Para os autores, a tese de Siqueira (1995) pode ser citada como exceção. Siqueira (1995) validou uma escala reduzida de percepção de suporte organizacional, adaptando o SPOS, desenvolvido por Einsenberg et al. (1986), de acordo com as características brasileiras.

Com o objetivo de construir um instrumento mais completo e adaptado às necessidades nacionais, Oliveira-Castro, Pilati e Borges Andrade (1999), investigaram a estrutura do suporte organizacional e desenvolveram um questionário denominado de Percepção de Suporte Organizacional. Tal questionário foi produzido e validado a partir de uma amostra de trabalhadores de empresas tanto privadas como de órgãos públicos, e estruturado em torno de quatro dimensões: gestão de desempenho, carga de trabalho, suporte material ao desempenho e ascensão, promoção e salários.

A primeira dimensão, caracterizada como gestão de desempenho, diz respeito à maneira como os trabalhadores enxergam as práticas organizacionais de gerenciamento do desempenho e produtividade do trabalhador. Consiste na avaliação de aspectos de valorização de novas ideias, conhecimento das dificuldades relacionadas à execução das tarefas e ao esforço organizacional de treinamento e capacitação de seus trabalhadores diante das novas tecnologias e processos de trabalho.

A segunda dimensão consiste na carga de trabalho e está relacionada à sobrecarga e ao excesso de exigências atribuídas aos funcionários quando há um aumento na produção, a obrigatoriedade de realizar horas extras, a transferência para locais não compatíveis com suas características e a desconsideração em decisões administrativas que o envolva.

O suporte material, terceira dimensão, consiste na percepção do trabalhador acerca da disponibilidade, adequação, suficiência e qualidade dos recursos materiais e financeiros 
disponibilizados pela organização para realização das tarefas. Consiste também, na modernização dos processos de trabalho e na qualificação dos trabalhadores.

Por fim, a última dimensão, refere-se a como o indivíduo percebe as práticas organizacionais de retribuição financeira, promoções e ascensão funcional, é denominada de práticas organizacionais de ascensão, promoção e salários.

Oliveira-Castro, Pilati e Borges Andrade (1999) verificaram que além das dimensões propostas, o suporte organizacional refere-se às crenças do trabalhador acerca do quanto a organização valoriza suas contribuições e cuida de seu bem-estar como um todo, não diferenciando o comportamento de trabalhadores específicos, como chefes e líderes.

Ainda no Brasil, Tamayo et al (2002, apud Tamayo; Tróccoli, 2000), desenvolveram e validaram a Escala de Suporte Organizacional Percebido - ESOP. Esta escala é composta por 42 itens divididos em seis dimensões. Assim como Oliveira-Castro, Pilati e BorgesAndrade (1999), Tamayo e Tróccoli (2002), identificaram os fatores gestão do desempenho, carga de trabalho, suporte material e ascensão e salários como influenciadores na percepção do suporte organizacional dos trabalhadores. Além dessas dimensões, os autores identificaram ainda fatores relacionados aos estilos de gestão da chefia e suporte social no trabalho.

O fator estilos de gestão de chefia refere-se à percepção que o trabalhador possui acerca das formas utilizadas pela chefia para colocar em prática políticas organizacionais, enquanto que o suporte social no trabalho está ligado à percepção do trabalhador quanto ao apoio social e a qualidade do relacionamento interpessoal.

Tamayo e Tróccoli (2002) realizaram um estudo com 369 trabalhadores ocupantes de diferentes cargos em empresas públicas e privadas dos setores bancário, de pesquisa e serviços com o objetivo de avaliar sob o ponto de vista da exaustão emocional, a percepção do suporte organizacional e o coping no trabalho. Os autores identificaram que os fatores gestão de desempenho, sobrecarga de trabalho, suporte social e ascensão e salários pertencentes à Escala de Suporte Organizacional Percebido revelaram-se preditores significativos da exaustão emocional.

Paschoal, Torres e Porto (2010), testaram o impacto do suporte organizacional e do suporte social das distintas dimensões relacionadas ao bem-estar no trabalho, com 403 servidores de uma organização pública. Como resultado, se identificou que o suporte organizacional e o suporte social possuem impacto direto no bem-estar dos trabalhadores. Neste caso, a gestão de desempenho apresentou-se como principal efeito de afeto positivo e realização no trabalho, enquanto que a carga de trabalho foi o principal efeito de afeto negativo.

Com o objetivo de compreender a influência dos valores organizacionais na percepção de suporte organizacional, Estivalete e Andrade (2012), realizaram estudo com 332 trabalhadores do setor bancário público e privado. O resultado demonstrou que o suporte organizacional apresentou um nível moderado de incidência. Para os autores, o resultado obtido pode estar relacionado à atribuição de menores índices de prioridade das organizações estudadas aos valores organizacionais, como bem-estar, autonomia e 
realização. Para Estivalete e Andrade (2012) esses valores estão relacionados com a qualidade de vida, satisfação e reconhecimento dos trabalhadores, o que resulta em menor incidência de suporte organizacional.

Brandão, Borges-Andrade e Guimarães (2012) pesquisaram a relação entre as competências expressas pelos gerentes de agências bancárias e a percepção deles sobre o suporte organizacional. A pesquisa foi realizada com 186 gerentes de agências e 77 superintendentes regionais de uma instituição bancária brasileira. Neste caso, apenas o fator práticas de gestão de desempenho apresentou efeito significante sobre o desempenho das agências pesquisadas. Os demais resultados apresentados demonstram que quanto melhor a percepção de suporte organizacional, melhor o resultado econômico da instituição.

Sant'anna, Paschoal e Gosendo (2012) testaram a relação do suporte organizacional para a ascensão, promoção e salários, e os estilos gerenciais com o bem-estar no trabalho.Tal pesquisa foi realizada com 157 trabalhadores de duas organizações privadas e identificou que tanto os estilos gerenciais quanto o suporte organizacional para a ascensão, promoção e salários apresentam relações significativas com o bem-estar no trabalho. $\mathrm{O}$ suporte organizacional obteve as relações mais significativas com os fatores de bem-estar e foi seu principal causador. Desse modo, os autores concluíram que quanto maior a percepção de suporte, maiores são o afeto positivo e a realização do empregado.

Silva, Cappellozza e Costa (2014) analisaram o impacto da percepção de suporte organizacional e comprometimento organizacional afetivo na intenção de rotatividade de 132 trabalhadores do estado de São Paulo. Os autores verificaram que tanto a percepção de suporte quanto o comprometimento organizacional tiveram impacto negativo significante na intenção de rotatividade dos empregados, entretanto, o comprometimento afetivo teve mais impacto que o suporte organizacional no que se refere à retenção de funcionários.

Assim como Silva, Cappellozza e Costa (2014), Diógenes et al. (2016) realizaram estudo a fim de verificar a influência da percepção de suporte organizacional na intenção de rotatividade de servidores públicos de um órgão da administração pública federal. Neste caso, a pesquisa foi aplicada a 112 participantes e revelou que os servidores possuem um elevado desejo em sair da organização pesquisada e avaliam negativamente o suporte organizacional, principalmente, o fator relacionado à ascensão, promoção e salários. Além disso, o fator voltado para a gestão de desempenho também possui grande influência na intenção de sair da instituição.

Os resultados apresentados mostram que as crenças nutridas pelos empregados com relação ao quanto a organização se preocupa e cuida do bem-estar de seus trabalhadores pode influenciar desde a satisfação, envolvimento e comprometimento, como também no absenteísmo, desempenho e intenção de rotatividade (Siqueira; Gomide, 2004).

\section{Rotatividade e intenção de rotatividade}

A rotatividade tem se revelado grande fonte de preocupação dos gestores de recursos humanos das organizações, e tem sido amplamente abordada no campo do comportamento 
organizacional, já que o estudo da conduta humana no ambiente de trabalho pode proporcionar às organizações, ganhos em competitividade e a rotatividade possui impacto direto sobre isso (Ferreira; Freire, 2001). Diante deste cenário, e considerando que os trabalhadores possuem poder direto nos resultados de produtividade alcançados pelas empresas, surge a necessidade de as organizações desenvolverem métodos e estratégias para atrair e manter os bons profissionais visando buscar maior competitividade.

Para Paschoal, Torres e Porto (2010), a preocupação por parte das organizações em valorizar seus funcionários, bem como a criação de condições necessárias para o bom desempenho de suas atividades e sua satisfação, vem aumentando devido à concorrência crescente e as aceleradas transformações no mundo do trabalho.

Segundo Siqueira e Gomide (2004), durante as décadas de 1960 e 1970, surgiram diversas alterações significativas na compreensão de fatores influenciadores nos resultados organizacionais oriundos da força de trabalho. Os autores ressaltam que a satisfação e o envolvimento com o trabalho foram objetos de diversas pesquisas que tinham como objetivo identificar os antecedentes que influenciavam nos níveis de produtividade e desempenho e nas taxas de absenteísmo e rotatividade dos trabalhadores.

De acordo com Agapito, Filho e Siqueira (2015), os estudos sobre a rotatividade de pessoal surgiram com Brayfiel e Crockett (1955) e Herzberg et al. (1959). Brayfield e Crockett (1955) além de encontrarem correlações entre a rotatividade e o absenteísmo, identificaram fragilidades metodológicas em diversos estudos.

Para Anselmi, Angerami e Gomes (1997), a rotatividade compreende "a medida do número de trabalhadores que passa pelos postos de trabalho, seção, empresa, setor ou ramo, num determinado período de tempo". Para os autores, os resultados obtidos podem ser classificados conforme as repercussões relacionadas à eficiência e produtividade da organização.

Segundo Mobley (1992), a rotatividade de pessoal significa a saída do trabalhador de uma organização na qual recebia compensação monetária pelos trabalhos realizados.

Para Mobley (1992) e Robbins (2002), a rotatividade pode ser classificada como involuntária, quando ocorre por iniciativa da organização ou voluntária, quando ocorre por iniciativa do funcionário. Robbins (2002) entende que a rotatividade voluntária parece ser a mais prejudicial às empresas, uma vez que pode representar a perda de pessoas estratégicas e com alto desempenho, causando prejuízos nos níveis de eficiência e produtividade organizacional. Para Assis (2005), o custo da rotatividade é um desafio para os gestores de recursos humanos das organizações. Para o autor, os custos estão relacionados desde a demissão, reposição, exames para demissão e admissão, tempo de reposição da vaga, treinamento e ambientação até a perda de produtividade.

Steers e Mowday (1981) explicam que o comportamento de um indivíduo que deseja sair da organização passa por diferentes etapas, que consistem na baixa expectativa de trabalho e valores compartilhados com a organização, em respostas afetivas negativas, na intenção de deixar a organização e nas oportunidades de melhores trabalhos. 
Segundo Vanderberg e Nelson (1999), a rotatividade significa a probabilidade subjetiva própria dos indivíduos, de deixar a organização em um futuro próximo, de modo que o simples desejo de sair pode ser chamado de intenção de rotatividade.

A intenção de rotatividade segundo com Perryer et al. (2010), pode ser considerada um fator que antecede a saída do empregado da organização. Assim, para ele, a intenção de rotatividade deve ser utilizada como variável importante em diversos estudos, pois permite medir no presente e em conjunto com outros fatores, as causas da rotatividade.

As causas que levam o indivíduo a sair voluntariamente da organização em que trabalha podem ser motivadas por diversos fatores. Para Ferreira e Freire (2001) os motivos mais citados na literatura são a política salarial; a política de benefícios, oportunidades de progresso profissional oferecida; tipo de supervisão; política disciplinar; condições físicas ambientais de trabalho e a motivação de pessoal.

Ferreira e Freire (2001) investigaram a inter-relação entre a carga de trabalho e a rotatividade de pessoal no cargo de frentista. Os autores concluíram que a rotatividade constante, ocorria devido ao fracasso das estratégias operatórias e aos esforços para condução de diversas exigências aliados a baixa remuneração.

Considerando que os elevados índices de rotatividade de pessoal podem comprometer significativamente os resultados organizacionais, Ferreira e Siqueira (2005) testaram um modelo para intenção de rotatividade, relacionando o comprometimento organizacional afetivo e satisfação no trabalho como antecedentes diretos e a percepção de justiça de remuneração como antecedente indireto. A pesquisa foi realizada com 81 profissionais de empresas do setor metalúrgico e eletroeletrônico do estado de São Paulo.Verificou-se que no setor metalúrgico o impacto maior sobre a intenção de rotatividade está relacionado à satisfação dos empregados no trabalho, enquanto que no setor de eletroeletrônico o comprometimento organizacional afetivo foi o fator que teve impacto direto na intenção de rotatividade dos empregados.

Campos e Malik (2008) pesquisaram a satisfação no trabalho dos médicos do Programa de Saúde da Família objetivando identificar os fatores que geram a rotatividade dos médicos do programa. Os resultados da pesquisa de satisfação no trabalho foram correlacionados aos dados de rotatividade. Os fatores que apresentaram maior correlação com a rotatividade foram capacitação, tempo de locomoção para chegar ao trabalho e a falta de materiais para realização das atividades.

Medeiros et al.(2010) realizaram um estudo de rotatividade dos médicos e enfermeiros que atuam na Estratégia de Saúde da Família e com base nos resultados da pesquisa concluíram que a alta rotatividade é condicionada por motivos tanto objetivos quanto subjetivos. As causas variam desde o vínculo precário de contratação e dificuldades de relacionamento com a chefia até a realização profissional nas atividades desenvolvidas.

Amaral e Lopes (2014) buscaram compreender, no âmbito da Universidade Federal de Pernambuco, a rotatividade dos servidores do corpo técnico-administrativo. O resultado da pesquisa revelou que os novos servidores da instituição buscam melhores salários e 
benefícios e que a disparidade nos valores dos benefícios e salários é um fator dificultador para a retenção desses servidores.

Patzlaff et al. (2015) estudaram os aspectos responsáveis pelo ingresso, permanência e evasão dos servidores técnico-administrativos de uma Instituição Federal de Ensino Superior. Os resultados da pesquisa mostraram que uma parcela significativa dos servidores apresentou intenção de sair da instituição em busca de melhores salários e crescimento na carreira.

Agapito, Filho e Siqueira (2015), com o objetivo de analisar, interpretar e discutir as relações entre as percepções de sucesso na carreira, o bem-estar no trabalho e a intenção de rotatividade de trabalhadores da Região Sudeste do Brasil, realizaram um estudo com 500 trabalhadores que atuam em organizações não governamentais, públicas e privadas do estado de São Paulo. Os resultados obtidos mostraram que as dimensões de bem-estar no trabalho exercem forte e significativo impacto na intenção de rotatividade, enquanto que a percepção de sucesso na carreira possui influência menor na intenção de deixar a organização. Os autores concluíram que quanto maior for a preocupação da organização em proporcionar um ambiente de trabalho satisfatório, menor será a intenção dos trabalhadores de deixá-la.

É importante observar que toda organização tem um determinado nível de rotatividade, entretanto, conforme explica Robbins (2002, p. 22), se as "pessoas certas" ou "funcionários não essenciais" começam a deixar a empresa, a rotatividade pode ser vista como um aspecto positivo, entretanto, a rotatividade quase sempre acarreta na perda de trabalhadores que a organização não gostaria de perder, o que pode prejudicar a produtividade e eficácia da organização.

\section{Considerações finais}

O presente trabalho teve como propósito realizar uma revisão de literatura acerca de questões relacionadas à percepção de suporte organizacional e a intenção de rotatividade. Foram analisadas pesquisas de autores nacionais e internacionais, realizadas em diferentes contextos organizacionais com base nos temas estudados. Tais pesquisas não necessariamente foram realizadas com o objetivo de correlacionar as duas questões, entretanto, demonstraram que a intenção de deixar a organização por parte do trabalhador, está ligada a diversos fatores, entre eles, a percepção de suporte organizacional, a satisfação no trabalho e ao bem-estar.

Diante disso, percebe-se que uma baixa percepção de suporte organizacional por parte dos trabalhadores, aliada a outros fatores podem despertar a intenção de rotatividade. Entretanto, conforme pontua Vanderberg e Nelson (1999), a intenção elevada de rotatividade não deve ser considerada como uma saída inevitável de um empregado.

Os resultados das pesquisas analisadas podem servir como instrumento de diagnóstico e avaliação organizacionais no planejamento estratégico das organizações. Além disso, 
também podem ser utilizados como indicadores na identificação de necessidades de se repensar as políticas organizacionais voltadas para o trabalhador.

A avaliação periódica da intenção de rotatividade e a mensuração da percepção dos servidores acerca de suas práticas organizacionais e políticas de gestão de pessoas podem ser uma boa alternativa para que os gestores possam desenvolver ou aprimorar práticas e políticas de modo a aumentar a percepção de suporte organizacional e a intenção de rotatividade por parte de seus trabalhadores.

\section{Referências}

AGAPITO, Paula Rodrigues; FILHO, Angelo Polizzi; SIQUEIRA, Mirlene Maria Matias. Bem-Estar no trabalho e percepção de sucesso na carreira como antecedentes de intenção de rotatividade. Revista de Administração Mackenzie, v. 16, n. 6, p. 71-93, nov./dez. 2015. Edição Especial.

AMARAL, Lenita Almeida; LOPES, Silvia Marise Araújo. Rotatividade de Pessoal no Serviço Público Federal: Um estudo de caso na UFPE. In: Congresso CONSAD de Gestão Pública,VII, 2014, Brasília. Disponível em: $<$ http://banco.consad.org.br/handle/123456789/1165>. Acesso em: 03 jun. 2017.

ANSELMI, Maria Luiza;ANGERAMI, Emília Luigia Saporiti; GOMES, Elizabeth Laus Ribas. Rotatividade dos trabalhadores de enfermagem nos hospitais do município de Ribeirão Preto. Revista Panamericana de Salud Pública, v. 2, n. 1, p. 44-50, 1997.

ASSIS, Marcelino Tadeu de. Indicadores Demográficos. In: ASSIS, Marcelino Tadeu de. Indicadores de Gestão de Recursos Humanos: Usando indicadores demográficos, financeiros e de processos na gestão do Capital Humano. Rio de Janeiro: Ed. Qualitymark, 2005. p. 19-61.

BRANDÃO, Hugo Pena;BOR GES-ANDRADE, Jairo Eduardo; GUIMARÃES, Tomás de Aquino. Desempenho organizacional e suas relações com competências gerenciais, suporte organizacional e treinamento. Revista de Administração, v. 47, n. 4, p. 523-539, out./nov./dez. 2012.

BRAYFIELD, Arthur H; CROCKETT, Walter H. Employee attitudes and employee performance. Psychological Bulletin, v. 52, p. 396-424, 1955.

CAMPOS, Claudia Valentina de Arruda Campos; MALIK, Ana Maria. Satisfação no trabalho e rotatividade dos médicos do Programa de Saúde da Família. Revista de Administração Pública, Rio de Janeiro, v. 42, n. 2, p. 347-368, mar./abr. 2008.

DIÓGENES, Larissa Coutinho et al. Intenção de rotatividade e percepção de suporte organizacional em um órgão público federal. Revista do Serviço Público, v. 67, n. 2, p. 147-172, abr./jun. 2016.

EISENBER G, Robert et al. Perceived organizacional support. Jounal of Applied Psychology, v. 71, n. 3, p. 500-507, 1986.

EISENBERG, Robert et al. Perceived supervisor support: Contributions to perceived organizational support and employee retention. Journal of Applied psychology, v. 8, n. 3, p. 365-573, 2002.

ESTIVALETE, Vania de Fátima Barros; ANDRADE, Taís. A influência dos valores organizacionais na percepção de suporte organizacional com base na concepção dos colaboradores do setor bancário. Revista de Administração Mackenzie, v. 13, n. 3, maio/jun. 2012. Ed. Especial.

FERREIRA, Maria Luiza Conceição Bisi; SIQUEIRA, Mirlene Maria Matias. Antecedentes de intenção de rotatividade: estudo de um modelo psicossocial. Organizações em contexto, Ano 2, n. 2, p. 47-67, dezembro, 2005.

FERREIRA, Mário César; FREIRE, Odaléa Novais. Carga de trabalho e rotatividade na função de frentista. Revista de Administração Contemporânea, v. 5, n. 2, p. 175-200, maio/ago. 2001. 
HARMAN, Willis; HORMAN, John. O trabalho criativo - o papel construtivo dos negócios numa sociedade em transformação. São Paulo: Cultrix, 1992.

HERZBERG, Frederick et al. Job attitudes: review of research and opinion. Industrial and Labor Relations Review, v. 12, p. 320-322, 1959.

LEVINSON, Harry. Reciprocation: the relationship between man and organization. Administrative Science Quarterly, v. 9, p. 370-390, 1965.

MEDEIROS, Cássia Regina Gotler et al. A rotatividade de enfermeiros e médicos: um impasse na implementação da Estratégia de Saúde da Família. Ciência e Saúde Coletiva, v. 15, supl. 1, p. 1521-1531,jun. 2010.

MOBLEY, William H. Turnover: causas, consequências e controle. Porto Alegre: Ortiz, 1992.

OLIVEIRA-CASTRO, Gardênia Abbad;PILATI, Ronaldo;BOR GES-ANDRADE, Jairo Eduardo. Percepção de Suporte Organizacional: Desenvolvimento eValidação de um Questionário. Revista de Administração Contemporânea, v. 3, n. 2, p. 29-51, maio/ago. 1999.

PASCHOAL, Tatiane; TORRES, Cláudio Vaz; PORTO, Juliana Barreiros. Felicidade no trabalho: Relações com Suporte Organizacional e Suporte Social. Revista de Administração Contemporânea, v. 14, n. 6, p. 1054-1072, dez. 2010.

PATZLAFF, Priscila Maria Gregolin et al. Gestão de Recursos Humanos: aspectos motivacionais responsáveis pelo ingresso e permanência dos trabalhadores em uma Instituição Federal de Ensino. Nucleus, v. 12, n. 2. p. 87-109, out. 2015.

PERRYER, Chris et al. Predicting turnover intentions: the interactive effects of organizational commitment and perceived organizational support. Management Research Review, v. 22, Iss. 9, p. 911-923, 2010.

ROBBINS, Stephen P. Comportamento organizacional. 9. ed. São Paulo: Prentice Hall, 2002.

SANT'ANNA, Liliane Lima; PASCHOAL, Tatiane; GOSENDO, Eliana Elisabete Moreira. Bem-estar no trabalho: relações com estilos de liderança e suporte para ascensão, promoção e salários. Revista de Administração Contemporânea, v. 16, n. 5, p. 733-764, set./out. 2012.

SIQUEIRA, Mirlene Maria Matias. Antecedentes de comportamentos de cidadania organizacional: a análise de um modelo pós-cognitivo. Brasília: Universidade de Brasília, 1995.

SIQUEIRA, Mirlene Maria Matias. Esquema mental de reciprocidade e influências sobre afetividade no trabalho. Estudos de Psicologia, v.10, n. 1, p. 83-93, 2005.

SIQUEIRA, Mirlene Maria Matias; GOMIDE, Sinésio Júnior. Vínculos do indivíduo com a organização e com o trabalho. In: ZANELLI, José Carlos; BORGES-ANDRADE, Jairo Eduardo; BASTOS, Antonio Virgílio Bittencourt (Org.). Psicologia, organizações e trabalho no Brasil. Porto Alegre: Artmed, 2004. p.300-328.

SIQUEIRA, Mirlene Maria Matias; PADOVAM,Valquíria Aparecida Rossi. Bases teóricas de bem-estar subjetivo, bem-estar psicológico e bem-estar no trabalho. Psicologia:Teoria e Pesquisa, v. 24, p. 201-209, 2008.

SILVA, Rogério dos Santos; CAPPELLOZZA, Alexandre; COSTA, Luciano, Venelli. O impacto do suporte organizacional e do comprometimento afetivo sobre a rotatividade. Revista de Administração IMED, v. 4, n. 3, p. 314-329, ago./dez. 2014.

STEERS, Richard M.; MOWDAY, Richard T. Employee turnover and post decision accommodation processes. Research in Organizational Behavior, v. 3, p. 235-281, 1981.

TAMAYO, Mauricio Robayo;TRÓCCOLI, Bartholomeu Tôrres. Exaustão emocional: relações com a percepção de suporte organizacional e com as estratégias de coping no trabalho. Estudos em Psicologia, v. 7, n. 1, p. 37-46, 2002.

VANDENBERG, Robert J.; NELSON, Jodi Barnes. Desegregating the motives underlying turnover intentions: When do intentions predict turnover behavior? Human Relations, v. 52, n. 10, p. 1313-1336, 1999. 


\title{
Design of organizational support and intention of rotational activity based on the literature
}

\begin{abstract}
This work had the objective of elaborating a literature review about the perception of organizational support and intention of rotation. In order to reach this objective, works of the national and international literature on the themes were analyzed. Despite the selected studies do not correlate the perception of organizational support with the intention of turnover of workers, they have shown that low support perception can lead to consequences such as absenteeism and turnover intention. The studies were not necessarily proposed by the authors, with the objective of correlating the perception of organizational support with the intention of workers' turnover, however, they showed that the low perception of support can lead to consequences such as absenteeism and the intention of rotation. In addition, they also demonstrated that the intention to leave the organization may be related to several factors, among them, the low level of perception of organizational support, job satisfaction and worker well-being.
\end{abstract}

Keywords: Organizational support, job satisfaction, turnover.

\section{Concepción de soporte organizacional e intención de rotatividad con base en la literatura}

\section{Resumen}

Este trabajo tuvo como objetivo presentar una revisión de literatura acerca de la percepción de soporte organizacional e intención de rotatividad. Para ello, el foco recayó en marcos referenciales y artículos de la literatura nacional e internacional sobre los referidos temas.Aunque las investigaciones seleccionadas no correlacionan la percepción de soporte organizacional con la intención de rotación de los trabajadores, evidenciaron que la baja percepción de soporte puede llevar a consecuencias como el absentismo y la intención de rotatividad. Además, también demostraron que la intención de dejarla organización puede estar relacionada a diversos factores, entre ellos, el bajo nivel de percepción de soporte organizacional, la satisfacción en el trabajo y el bienestar del trabajador.

Palabras clave: Soporte organizacional, satisfacción en el trabajo, rotación. 